Fecha de recepción: febrero 2019 Fecha de aceptación: julio 2019 Versión final: noviembre 2020

\section{Transgamificación y cultura: del videojuego como producto cultural al videojuego como totalidad cultural}

Guillermo Sepúlveda Castro *

Resumen: Hoy por hoy, en pleno siglo XXI, la Gamificación (aplicación del pensamiento de juegos en contextos no lúdicos) ha dejado de ser una metodología productivista y ha iniciado un duro proceso de colonización cultural en aquellos espacios no-productivos. Y es que hoy surgen voces que exigen que la Gamificación apele a mucho más, exigiéndole llegar, inclusive, a la vida misma.

Esta exigencia de desborde puede ser traducida en una expansión socio-política sin igual de los códigos y categorías de la cultura, comúnmente ligados al juego y al ocio. A este fenómeno colonizador se le denomina Trans-gamificación. El presente artículo abordará sus orígenes, así como sus proyecciones a nivel filosófico y político.

Palabras clave: Gamificación - Trans-gamificación - ocio - juego - sociedad.

[Resúmenes en inglés y portugués en la página 187]

${ }^{(*)}$ Chileno, Magíster en Gestión de Personas en Organizaciones de la Universidad Alberto Hurtado y Sociólogo de la Universidad de Concepción. Se ha desempeñado como Docente en el Instituto Profesional Arcos (2014-2017) y en el Instituto Valle Central (2018). Actualmente es Investigador independiente de videojuegos, docente de la cátedra "Juegos y Sociedad" en la Universidad SEK y Game Manager de una empresa que desarrolla Gamification denominada "BadgeHeroes". Adicionalmente es gestor de redes de pensamiento en torno a los videojuegos y fundador del Ciclo de Conversaciones en torno a los videojuegos "El último Arte". Ha escrito de diversas temáticas que van desde lo patrimonial con títulos como "Arquitectura de la Memoria (2010)", sobre autores del Centenario con títulos como "Nicolás Palacios: pasión y doctrina (2012)" y de ciencias políticas, "Incorrectus: Análisis y crítica del discurso postmoderno (2016)".

Cada época tiene su forma de contar historias, y el videojuego es una gran parte de nuestra cultura. Puedes ignorar los videojuegos o aceptarlos y empaparte de su gran calidad artística. (Andy Serkis.) 


\section{Videojuegos: Lo que son y han dejado de ser}

"Los videojuegos son tal vez la avanzadilla de un mundo producido en serie, pero a la hechura de cada uno" (Levis)

Estamos en pleno Siglo XXI y convivimos día tras día con diversas instancias, tanto serias como de ocio. La industria de los videojuegos -sea porque jugamos alguna vez, seguimos jugando u otras generaciones lo hacen- es una realidad cultural. Evitarla es casi imposible, al punto que inclusive personas que no saben nada del tradicional mundo de las consolas, juegan ahora de manera casual (casual gamers) en sus móviles.

Hoy por hoy, ya podemos hablar de una verdadera industria que obtuvo unos ingresos de más de 75.000 millones de dólares en el 2014, de acuerdo con las estimaciones. Está muy cerca de la industria del cine (90.000 millones de dólares) y crece a una media del $6 \%$ anual, más rápido que el cine (menos del 3\%, según Statista). Eso es lo que afirman los estudios realizados por Newzoo el mismo año en ciudades como Mexico (Newzoo, 2018), dejando así en claro que no sólo es un fenómeno europeo o norteamericano.

Sumado a lo anterior, ya hay en el planeta más de 1.200 millones de aficionados a los videojuegos, y los mercados que más crecen son América Latina y Asia: un $11 \%$ al año (Newzoo, 2018).

¿Qué tipo de implicancia social conlleva la reproducción cultural de esta industria masiva de consumo? ¿Conlleva esto únicamente una implicancia social en quienes juegan o puede ampliarse igualmente a quienes no lo hacen?

Para iniciar una reflexión en torno al tema, urge definir conceptos claves, desarrollarlos conceptualmente y, por sobretodo, contextualizarlos en su propia época.

Considerando esto como inicio de esta travesía textual, es hora de empezar a "jugar" y conocer sus implicancias socio-culturales en lo que comprenderemos por Video-juego, Gamificación y Trans-gamificación.

\section{Video-juego: Definiciones significativas para su comprensión en contexto.}

El vocablo Video-juego es una palabra compuesta. Etimológicamente, la palabra videojuego proviene del verbo latino "video", vides, videre, que se traduce como el verbo 'ver'. Se suele aplicar este término a la señal de video y muchas veces se la denomina «el video»o «la video», a modo de abreviatura del nombre completo de la misma. De ahí que su materialización social sea sintetizada como: "Uso de tecnología de la captación, grabación, procesamiento, almacenamiento, transmisión y reconstrucción por medios electrónicos, digitales o analógicos de una secuencia de imágenes que representan escenas en movimiento". La palabra que completa el concepto es “juego", que remite al vocablo latín 'iocus', que significa 'broma'. Puede afirmarse acerca del juego que se trata de una actividad realizada por seres humanos, que involucra el desenvolvimiento de la mente y el cuerpo, con un sentido lúdico, de distracción, de diversión y aprendizaje.

Autores como Huizinga (1938) lo definen como: 
"El juego, en su aspecto formal, es una acción libre, ejecutada "como si" y sentida como situada fuera de la vida corriente, pero que, a pesar de todo, puede absorber por completo al jugador, sin que haya en ella ningún interés material ni se obtenga en ella provecho alguno, que se ejecuta dentro de un determinado tiempo y en un determinado espacio, que se desarrolla en un orden sometido a reglas y que da origen a asociaciones que propenden a rodearse de misterio o a disfrazarse para destacarse del mundo habitual (p. 27).

La definición de Huizinga contribuye a dar una mirada práctico-social al juego, ya que le otorga vida a un concepto considerado por muchos como mero "pasatiempo". Pero quizás la perspectiva más significativa de este autor es la relación que éste encuentra con la cultura humana.

Huizinga reconoce que "el juego es más antiguo que la cultura" y que su realidad "no puede basarse en ninguna conexión de tipo racional". Es más: llega a plantear que, en cierto sentido, la cultura siempre será jugada, según cierto acuerdo mutuo que adopta determinadas reglas de juego. Desde variados puntos de vista, la verdadera civilización exige el fair play (juego limpio), lo que en términos lúdicos equivale a buena fe. El alejamiento del juego puede llegar a quebrantar o distorsionar la propia cultura (Huizinga, 1938: 337).

Esta relación simbiótico-constructiva entre juego y cultura ofrece aperturas reflexivas que dignifican su importancia.

Con ello y, considerando que el juego es una actividad esencial en el hombre, autores como Roger Caillois (1991) prefieren profundizar en las tipologías de juegos subyacentes en toda cultura, así como operacionalizar de mejor forma el concepto en términos estructurales.

¿Qué entiende Callois por juego? Según Callois, el juego se compone de al menos seis elementos constituyentes (Palillero, 2012):

- Libre: Es una actividad libre y voluntaria porque le sirve al jugador para escaparse de la vida corriente de tal forma que se debe realizar cuando el jugador tenga ganas entregándose a él espontáneamente y sin ser obligado.

- Separado de la vida corriente: Siendo una ocupación separada del resto de la cotidianidad debe ser realizada dentro de límites precisos de tiempo y de lugar. - Incierto: Su desarrollo no puede estar predeterminado y la duda sobre el resultado debe prolongarse hasta el final, pues de no ser así se perdería el interés; ejemplo de esto son los juegos de habilidad, como el ajedrez, que no divertiría si se sabe que alguien va a ganar sin esfuerzo e infaliblemente ya que la diversión se encuentra en la posibilidad de un fracaso del jugador.

- Improductivo: El juego no crea ninguna riqueza u obra, en lo que se distingue del trabajo y del arte. Al final de la partida, todo puede y debe volver a empezar en el mismo punto. Es decir, solamente hay un desplazamiento de propiedades. - Reglamentado: Al realizarse dentro de cierto espacio y tiempo es necesario que en estos se sustituyan las leyes de la vida ordinaria por reglas precisas, arbitrarias e irrecusables, que es preciso aceptar como tales y que presiden el desarrollo correcto de la partida. Cuando existe un tramposo, este finge respetar 
las reglas aunque no sea así pero no destruye el juego ya que aunque las rompe proclama su validez con la intención de no ser descubierto. Quien destruye el juego es la persona que se niega a jugar denunciando lo absurdo de las reglas.

- Ficticio: La acción es acompañada de una conciencia específica de la realidad secundaria o de franca irrealidad en comparación con la vida corriente. Es una característica propia de los juegos de representación.

Como vemos, existen ciertas coincidencias con la definición de Huizinga, sin embargo Callois agrega determinados elementos que contribuyen a complementar la conceptualización del juego, así como dar pie a reconocer en el juego una diversidad del mismo no mencionada por Huizinga.

El aporte que vuelve interesante su mirada en torno al "juego" es su diferenciación en 4 tipos: Agon (competencia); Alea (suerte); Mimicry (simulacro o imitación) y Ilinx (vértigo).

- Agon (competencia): Son los juegos que aparecen como una lucha en donde se crea una igualdad artificial para que los antagonistas se enfrenten en condiciones ideales (aunque no es del todo posible), con posibilidad de dar un valor preciso e indiscutible al triunfo del vencedor. Ejemplos: fútbol, tenis, ajedrez. Este tipo de juegos requiere entrenamiento, disciplina y perseverancia, puesto que deja solo al jugador con sus recursos para aprovecharlos lo mejor posible. - Alea (suerte): En éstos, los participantes tratan de salir favorecidos por el destino, tienen la función de abolir las cualidades naturales o adquiridas de los individuos, dejándolos en igualdad absoluta de condiciones frente a la suerte. Ejemplos: Los dados, cara o cruz, etc. Lo arbitrario mismo es el resorte del juego. - Mimicry (simulacro o imitación): Consiste en ser uno mismo un personaje ilusorio y conducirse en consecuencia. El sujeto juega a creer, a hacerse creer o hacer creer a los demás que es distinto de sí mismo. En estos juegos, los disfraces o máscaras tienen como función cambiar la apariencia del portador y generalmente dar miedo a los demás jugadores. Entran aquí la representación teatral y la interpretación dramática.

- Ilinx (vértigo): Reúne a los juegos que consisten en un intento de destruir, por un instante, la estabilidad de la percepción y de infligir a la conciencia lúcida una especie de pánico voluptuoso, es decir, los jugadores buscan aturdirse provocando la aniquilación de la realidad con brusquedad. Ejemplo: dar vueltas, los voladores de Papantla, juegos mecánicos.

Autoras como Katya Mandoki agregan igualmente al tipo de juegos denominado "Peripatos" (explorar) centrados en el "jugar a conocer o descubrir algo" (Mandoki, 2006, 133). Complementariamente, queda recalcar que estos tipos de juegos, hoy en día, se encuentran fusionados, generando mayores diversificaciones. Ejemplos de ello, lo encontramos en juegos digitales como Fortnite (2017) en donde el tipo de juego pre-dominante es agon (competitivo), pero se entremezcla fácilmente con mimicry (simulacro o imitación) al incluir "skins" o vestimentas para personalizar a tu avatar, a su vez que implementa muy 
bien la exploración de espacios abiertos y desconocidos, haciendo tributo al tipo de juego peripatos (exploratorio).

Esta tendencia a la fusión de tipos de juegos lo plantea muy gráficamente Katya Mandoki: "Los juegos no siempre se presentan en estado puro al traslaparse unos con otros. Varían los efectos lúdicos de los diversos juegos entre la re-presentación del mimicry, el retozo del ilinx, la palpitación del alea, la emulación del agon y la aventura del peripatos. (...) La competencia implica al desafío que, a diferencia de los otros efectos, resulta siempre en un ganador y un perdedor: lo que se busca en el agon es el trofeo. El retozo del ilinx genera vértigo y la agudización de algún sentido en el movimiento para tratar de mantener el equilibrio. La aventura del peripatos consiste en desviarse del camino rutinario hacia una alternativa distinta" (Mandoki, 2006, 136)

Las afinaciones teórico-conceptuales recién mencionadas en torno al juego atribuyen a este una propiedad de "constituyente cultural", más que ser únicamente una producción de la cultura. Pasa a ser, bajo esta perspectiva, no sólo un "producto cultural", sino una "plataforma constituyente de cultura".

Con ello planteamos que los juegos son cultura, pero además ayudan a constituirla. Es decir, derivan de la cultura, pero además son vías que permiten canalizar distintas motivaciones, experiencias, sentimientos, emociones, ideas, creencias y, con esto dicho, intereses culturales de todo tipo. Lo dicho anteriormente, plantea que los tipos de juegos mencionados por Callois, no son solo "posibilidades creativas", sino, los canales en los que el ser humano se desenvuelve culturalmente.

En ello, los videojuegos no quedan atrás. En su mayoría son hibridaciones de los tipos de juegos mencionados por Callois y, por ende, ofrecen aún mayor potencial de canalización del desenvolvimiento cultural del ser humano.

Dicho lo anterior, la palabra videojuego comprendida como concepto significará, para efectos de este artículo: “juego digital". Pero si tomamos en cuenta que el juego es, según lo mencionado anteriormente, una plataforma constituyente de cultura, esto mismo lo re-define como: un aparato de reproducción de creencias, así como una plataforma de producción de verdades y necesidades humanas (competición, vértigo, simulacro, exploración y suerte).

El potencial sociológico de esta plataforma constituyente de cultura, guarda relación con la noción de que su potencial no yace tanto en su atractivo lúdico-distractivo, sino más bien en su capacidad para engendrar creencias y canalizarlas, volviendo así al juego-videojuego un medio más que un fin en sí mismo.

Complementariamente, la generalización de aplicaciones informáticas, particularmente a través de internet, en las que se aplican muchos de los recursos propios de las creaciones digitales más lúdicas, conformaron las condiciones previas para la instalación de una verdadera "colonización de lo lúdico" (Sepúlveda, 2016). Es así como ha emergido un fenómeno como la Gamificación, el cual puede ser comprendido como una expansión de utilidad cultural del videojuego, así como un verdadero movimiento generador de procesos socio-culturales nunca antes alcanzados por la esfera del juego. Esta penetración cultural del juego y las prácticas del ser humano en la sociedad es recalcada por autores como Mandoki, quien reconoce al juego como esencia más que mera práctica: 
"El juego no es una actividad que se realiza al margen de los deberes y haceres de la vida cotidiana, sino que ésta depende íntimamente del elemento lúdico para involucrar a los sujetos en su quehacer. Habiendo juego, hay vivencia, es decir, involucramiento afectivo, corporal y sensible de los sujetos con su actividad" (Mandoki, 2006: 142)

En el presente artículo, la Gamificación será considerada como un cambio evolutivo tecno-cultural del videojuego en sí y, en definitiva, una amplificación de su uso, reproducción y consistencia. Con ello, se establece a la Gamificación como un hito en el proceso de expansión de la plataforma juego-videojuego y una verdadera transmutación conceptual de su existencia.

\section{Introduciéndose a una nueva realidad gaming: La Gamificación.}

"Hay que destacar que el juego tiene un papel relevante en todas las facetas de nuestra vida y que el propio concepto del juego es consustancial al de nuestra existencia individual, aprendizaje y socialización. La gamificación ha sido, es y será un proceso consustancial al ser humano." (Flavio Escribano)

Que los videojuegos transmiten historias y relatos del sentir de nuestra época es algo más que conocido. Desde que los videojuegos surgieron, fueron instalándose en nuestra cultura contemporánea a un ritmo vertiginoso. De ser únicamente herramientas tecnológicas de entretenimiento, pasando por ser instancias de narración hasta llegado a ser hoy, finalmente, herramientas de transformación social (González, 2013: 134). De esta última fase, surge el modelo de la Gamificación.

La Gamificación, castellanización de Gamification, es un movimiento de reciente creación que utiliza las estructuras de jugabilidad de los videojuegos para aplicarlas al mundo real (Cortizo et al., 2011; Lee \& Hammer, 2011).

Según autores como Sebastián Deterding (2011): "La Gamificación es el uso de elementos del diseño de juegos en contextos no-lúdicos".

Esta idea surge de intentar utilizar el potencial motivador intrínseco observado en los videojuegos (elemento lúdico-distractivo) (Bunchball, 2010), transfiriéndolo a otras actividades no relacionadas con este ámbito (McGonigal, 2011), como por ejemplo las tareas domésticas, el rendimiento laboral o la fidelización de usuarios (González, 2014: 141).

¿Cuál es su objetivo? La Gamificación trata de conseguir que las tareas que, normalmente, son realizadas sin mucho entusiasmo se conviertan en situaciones más agradables y significativas, impulsando que el usuario llegue al "estado de ánimo que corresponde al juego (...) el arrebato y entusiasmo" (Huizinga, 2008, p. 168).

¿Cómo se enraizó esto en términos socio-culturales? ¿Y por qué hablar de este concepto en términos sociológicos?

Todo empezó con la gran revolución web y el surgimiento de Internet, el cual ha ido acelerando intensamente la creación de comunidades de gamers en torno a todo tipo de 
redes sociales, aplicaciones y páginas Web y en donde la estimulación del comportamiento de los usuarios, a través de técnicas de Gamificación, ha llegado a niveles insospechados. Si bien es cierto el fenómeno de los videojuegos ya había generado grandes transformaciones sociales en su auge de los 80-90, fue sólo con Internet que esto se vio potenciado de forma radical. Ejemplo de ello fue la masificación de los denominados "juegos online". Pionero de ello fue Doom (1993), que marcó un hito, no solo en la proliferación posterior de los juegos online, sino que además, de nuevos jugadores de mayor edad.

La Gamificación es el resultado de esto, así como el inicio de un nuevo proceso en la evolución del juego-videojuego, en donde este es más cercano a una mayor cantidad de personas de manera global.

Adicionalmente, la idea de introducir estructuras de juego (y de videojuego) a las actividades más triviales no sólo no es nueva, sino que prácticamente desde siempre se ha utilizado en contextos como la educación y últimamente en las empresas, con objeto de hacer más atractivas estas actividades de aprendizaje o formación (2). Y es que en realidad el Movimiento (contemporáneo) de la Gamificación tiene ya más de 10 años en vida. Este movimiento tiene sus orígenes en el año 2008, tal y como lo plantean sus seguidores, y emerge a raíz de la explosiva expansión de la industria de los videojuegos:

"La integración de dinámicas de juego en entornos no lúdicos no es un fenómeno nuevo, pero el crecimiento exponencial del uso de videojuegos en los últimos años ha despertado el interés de expertos en comunicación, psicología, educación, salud, productividad -y casi cualquier área de actividad humana-, por descifrar las claves que hacen del videojuego un medio tan eficaz. En estos últimos años ha comenzado también la expansión en el estudio de su aplicación a otros ámbitos no necesariamente lúdicos. Gamificación es el término escogido para definir esta tendencia." (Portal Gamificación.com)

El Movimiento de la Gamificación ha otorgado una verdadera revolución conceptual en lo referente a la relación entre lo ludológico (referente a los juegos y videojuegos) y la sociológico (referente a lo social). Con esto en mente, se puede concebir la Gamificación como un cambio en la manera de percibir y actuar en el mundo real desde el mundo real (McGonigal, 2011).

Los grandes beneficios de la Gamificación son, según expertos en la materia:

a) Convierte tareas tediosas y/o aburridas en atractivas (Cortizo et al., 2011).

b) Fomenta la participación del usuario (Bunchball, 2010; Lee \& Hammer, 2011).

c) Fideliza a los usuarios a partir de refuerzos y castigos (Zichermann \& Linder, 2013).

A su vez, en Mayo del año 2012, M2Research publicó un estudio en el que se recogían los principales objetivos declarados por empresas que estaban realizando Gamificación. La investigación arrojó los siguientes resultados: 
a) El $47 \%$ de las empresas consultadas estaban destinadas a aumentar la participación o compromiso del usuario, lo que en términos de negocio se traduce en aumentar registro e interacción, visitas, conversión, etc.

b) El $37 \%$ en aspectos de marketing; concretamente el 22\%, para incrementar la lealtad con la marca; y el 15\% para lograr notoriedad.

c) El 16\% con aspectos organizativos, distribuyéndose un $9 \%$ con fines motivacionales y el 7\% para formación y aprendizaje. (Asociación Española de Empresas Productoras y Desarrolladoras de Videojuegos y Software de Entretenimiento., 2014)

Algunos ejemplos y sus relatos de éxito hablan por sí solos:

"Hemos asistido a grandes casos de éxito en el mundo de la Gamificación, como es el caso de Starbucks o Coca-Cola, que te invita a bailar con sus máquinas expendedoras, premiando las mejores ejecuciones, o incluso hemos podido comprobar cómo la gamification ha conseguido que muchas personas que utilizaban en mayor o menor medida la banca electrónica, hayan aprendido a sacar mayor partido de ella y a incrementar su uso con experiencias como BBVA Game, juego en el que ya participan más de 135.000 usuarios y que ha sido premiado y reconocido mundialmente como uno de los mejores casos de éxito en Gamificación. Nike Plus o FuelBand, Toque Cepsa, o Adidas MyCoach son otros buenos ejemplos de esta excelente estrategia, a la que ya se han sumado marcas tan reconocidas como Toyota, Audi, El Corte Inglés, Chupa Chups, Deloitte, Repsol y otras importantes firmas. Está claro que la gamificación no deja indiferente a nadie que la conoce y aplica, y en la mayor parte de los casos, las marcas, una vez que la prueban, quieren más" (Asociación Española de Empresas Productoras y Desarrolladoras de Videojuegos y Software de Entretenimiento, 2014: 14).

Estos ejemplos, no obstante, demarcan la esfera más "utilitarista" de la Gamificación, que puede ser el inicio de un proceso aún mayor. Dicho esto, la Gamificación puede ser clasificada de la siguiente manera:

a. Gamificación productivista o tradicional: Caracterizada por centrarse en la implementación de pensamiento y mecánicas de juego en contextos cerrados ligados al sistema productivo (gestión de personas, educación, etc.). Aquí caben todas las aplicaciones de este proceso a los ámbitos considerados "rentables" para el sistema productivo.

b. Gamificación no-productivista o anti-tradicional: Caracterizada por centrarse en la implementación de pensamiento y mecánicas de juego en contextos abiertos y ligados a lo que está fuera de las empresas y colegios.

Esta última da pie a pensar en la aplicación de la lógica de juegos, no sólo para "cumplir indicadores", sino que más bien para potenciar el desarrollar habilidades sugeridas para la vida (Super Better, app diseñada y creada por Jane McGonical es un excelente ejemplo de ello el año 2017). 
Con este último tipo de Gamificación, los horizontes del juego-videojuego se amplían aún más, superando de manera definitiva el elemento lúdico-distractivo para transformar el desenvolvimiento cultural del ser humano y sus momentos de ocio en una nueva realidad con vida propia.

\section{4. ¿Y luego de la Gamificación, qué?}

"Cuando estamos en los mundos del juego, creo que muchos de nosotros nos convertimos en la mejor versión de nosotros mismos: los más propensos a ayudar en cualquier momento. Los más proclives a continuar con un problema, siempre que sea necesario. Para ponerse de pie después de la falla y volver a intentarlo." (Jane Mc Gonigal)

Lo que sucede actualmente es un proceso denominado "Gamificación de la vida" o "estructuración de la vida en base a lógicas de juegos-videojuegos". Cada vez más los videojuegos han empezado a convertirse en una industria que genera contenidos, pero a su vez, genera pautas de comportamiento, códigos para comprendernos entre nosotros, y una nueva forma de generar relaciones sociales. Dicho proceso socio-cultural lo denominaremos "Trans-gamificación" (Del griego "trans" que significa más allá, definiéndose, así dicho, como un "más allá de la Gamificación”).

Este proceso socio-cultural puede definirse como un proceso totalmente distinto a lo pretendido por la Gamificación tradicional o productivista y habla más bien de un deseo cultural de que la realidad sea un juego y, en estricto rigor, que los juegos traspasen el binario realidad seria/realidad lúdica.

Lo más revolucionario de este proceso es que es un fenómeno reproducido por las propias poblaciones y no tanto por expertos o especialistas. Es, en definitiva, un fenómeno que implica una "democratización de la gamificación" y es el "paso más allá de la Gamificación". Si en su momento la Gamificación planteó en sus inicios la "ludificación" de actividades y objetivos de contextos no-lúdicos, la Trans-gamificación aspira no sólo a ello, sino que sean las mismas personas (comunidades) las que ludifiquen sus contextos y realidades socio-culturales. Estaríamos hablando entonces de una superación conceptual de la Gamificación, que podría definirse de la siguiente forma: mientras que la Gamificación es el uso de los elementos del diseño de juegos en contextos no-lúdicos, la Trans-gamificación es la reproducción de nuevos elementos de juego en contextos ya ludificados.

Las diferencias entre Gamificación y Trans-gamificación radicarían en que, mientras la Gamificación requiere necesariamente de un experto o equipo de expertos para ludificar contextos no-lúdicos, la Trans-gamificación, por esencia, logra que los mismos "jugadores”, expandan el horizonte lúdico planificado por el equipo gamificador. Es decir, son los gamificados los que empiezan a gamificar.

Con todo, existe una radical diferencia entre la Gamificación y la Trans-gamificación y es que, considerando que la Trans-gamificación es reproducida por los jugadores, esta no es "experta", por ende, es trivial, pero no por eso menos profunda. Sus posibilidades van más 
allá del "diseño experto" y aspiran a desbordarlo, aceptando las propias sugerencias y la proactividad creadora de los jugadores (y nuevos gamificadores).

La Transgamificación, posee los siguientes impactos en los contextos-objetivo:

a. Ritualización en contextos gamificados: Estableciendo rutinas, ritos y costumbres que reflejan "valores sociales consensuados culturalmente" dentro de los entornos gamificados. Ejemplos de ello los encontramos en los grandes videojuegos de mundo abierto, tales como WOW (World of Warcraft, 2004) en donde los propios jugadores ejecutan matrimonios entre sus avatares o realizan reuniones triviales en lugares públicos del juego.

b. Sacralización de la sátira y el anonimato irresponsable: Resignificación de la máscara, considerado como avatar, en donde el jugador defiende normas políticamente incorrectas para el "mundo real", pero totalmente aceptadas en el "mundo ludificado" y bajo completo anonimato. Ejemplos de este tipo de práctica lo encontramos en las comunidades virtuales tipo foros, donde el concepto de "nickname" establece un anonimato claro, pero además se realizan burlas de toda índole (racista, xenófoba, etc.). Un caso muy evidente es el denominado "Nido" (Véase: https://www.nido.org/)

c. Transgresión constante de la realidad: En una búsqueda constante de "ludificarlo todo", se intenta invisibilizar el peso social de las normas culturales, intentando estar al margen del sistema cultural dominante (sea cual sea), desentendiéndose continuamente de sus lógicas, específicamente morales (Aquí el ejemplo de los memes como medio de comunicación válido entre las comunidades gamers es sumamente representativo de este punto). d. Constitución de un nuevo sujeto: Nacimiento de un nuevo sujeto, denominado neogamificador que escapa de las lógicas del "pensamiento de diseño experto", como consecuencia de lo anterior.

Este sujeto vive permanentemente alternando entre realidad "gamificada" y "no-gamificada”, sin aspiración de volver a los patrones culturales del viejo contexto no-lúdico.

Con ello en consideración, la Trans-gamificación aspira a empoderar, por ende, a los jugadores. Dándoles así una nueva identidad: los neo-gamificadores. Estos, a su vez, viven, cual fueran anfibios de la realidad, en una realidad trans-gamificada, sujetos a patrones alejados totalmente de los patrones sociales tradicionales y estableciendo nuevas posibilidades de gamificación permanente.

Es, quizás, el verdadero Homo Ludens de Huizinga el cual definiremos como:

"Un sujeto gamer activo que circula entre mundos gamificados y mundos por gamificar, envuelto en una lógica de expansión y colonización, diferente al gamer pasivo, admirador de sagas o de personajes icónicos. Con determinación a conquistar espacios mediante su afán creativo, donde destacan sus principales obras: fan-art, creación de personajes no-icónicos (Ver el caso de Bowsette en el año 2018), desarrollo de videojuegos propios e independientes, etc. Su "hábitat" es el el fandom (fan + kingdom = reino fan), pero al ser nómade y no sedentario, fluye entre comunidades, construye comunidades o a veces, por 
determinación propia, se excluye de las mismas para el mismo ser un gamificador autónomo. Su objetivo es uno: gamificar el mundo, volverlo lúdico"

¿Cuáles serán los multi-versos posibles creados por estos neo-gamificadores? ¿Será este el inicio de un nuevo movimiento cultural? He ahí, el dilema.

Estamos llegando a una situación cultural en que estas instancias lúdicas que llamamos juegos-videojuegos dejarán de ser "videos" (no requerirán de un video o video-consola) y "juegos” (dejarán de ser instantes lúdicos), al punto de asimilarse con la vida o realidad natural. Estaremos hablando en un tiempo más de una nueva realidad gaming y de cómo poco a poco los juegos-videojuego no solo derivarán de la cultura (por inspirarse en ella), sino que además serán ellos mismos una poderosa plataforma constituyente de cultura alternativa y derivada puramente de los neo-gamificadores. Y aún más importante: será una cultura que traspasará los "códigos formadores" que clásicamente posee la Gamificación, para re-crear nuevos "códigos morales".

Analizar sus implicancias a nivel mundial es tarea no solo investigativa, sino que además moral y política. Y he ahí su importancia como proceso, y, por qué no decirlo, de revolución cultural. ¿Hacia dónde queremos dirigir la Trans-gamificación? He ahí el dilema. Quizás próximamente sea relevante diferenciar entre "Trans-gamificación positiva" y "Trans-gamificación negativa" o ejercer otros tipos de diferenciaciones necesarias para la futura generación de reflexiones. He ahí el camino que pretendo seguir trabajando y espero que muchos más lo hagan conmigo.

\section{Notas}

1. Guillermo Sepúlveda Castro es Magíster en Gestión de Personas en Organizaciones de la Universidad Alberto Hurtado y Sociólogo de la Universidad de Concepción. Se ha desempeñado como Docente en el Instituto Profesional Arcos (2014-2017) y en el Instituto Valle Central (2018). Actualmente es Investigador independiente de videojuegos, docente de la cátedra "Juegos y Sociedad" en la Universidad SEK y Game Manager de una empresa que desarrolla Gamification denominada "BadgeHeroes". Adicionalmente es gestor de redes de pensamiento en torno a los videojuegos y fundador del Ciclo de Conversaciones en torno a los videojuegos "El último Arte". Ha escrito de diversas temáticas que van desde lo patrimonial con títulos como "Arquitectura de la Memoria (2010)", sobre autores del Centenario con títulos como "Nicolás Palacios: pasión y doctrina (2012)" y de ciencias políticas, "Incorrectus: Análisis y crítica del discurso postmoderno (2016)".

2. Con ello, podríamos hablar entonces de una "pre-historia" de la Gamificación, pero al no ser éste el objeto de este estudio, se recomienda a los interesados revisar el trabajo del Portal "A un clic de las TIC” y el breve ensayo titulado “Alguien más quiere discutir sobre la historia de la "gamificación?", realizado por el experto español en Gamificación Ángel González de la Fuente (A un clic de las TIC, 2016) 


\section{Listas de referencias bibliográficas.}

Asociación Española de Empresas Productoras y Desarrolladoras de Videojuegos y Software de Entretenimiento (2014). Obtenido de: www.dev.org.es/images/stories/docs/LibroBlancoDEV\%20alta_compr.pdf.

A un ciclo de las tic. ¿Alguien más quiere discutir sobre la historia de la "gamificación"?. Obtenido de: https://aunclicdelastic.blogthinkbig.com/alguien-mas-quiere-discutirsobre-la-historia-de-la-gamificacion/

Bonsignore, E (2012)., et al. "Mixed reality games." Proceedings of the ACM 2012 conference on Computer Supported Cooperative Work Companion. ACM, 2012. doi:10.1145/2141512.2141517

Bunchball. (2010). Gamification 101: An Introduction to the Use of Game Dynamics to Influence Behavior. (I. Bunchball, Ed.) Recuperado el 17 de agosto de 2016, de Bunchball: Obtenido en: http://www.bunchball.com/sites/default/files/downloads/gamification101.pdf

Cortizo, J., Carrero, F., Monsalve, B., Velasco, A., Diaz Del Dedo, L., \& Perez, J. (2011). Gamificación y Docencia: Lo que la Universidad tiene que aprender de los Videojuegos. Madrid. España.

Deterding, S., Dixon, D., Khaled, R., \& Nacke, L. (2011, September). From game design elements to gamefulness: defining gamification. In Proceedings of the 15th international academic MindTrek conference: Envisioning future media environments (pp. 9-15). ACM.

El nido (2018). Obtenido en: https://www.nido.org

Frith, J. (2013) Turning life into a game: Foursquare, gamification, and personal mobility. Mobile Media \& Communication 1.2: 248-262. USA.

Gonzalez, C. (2014) Videojuegos para la Transformación Social. Tesis Doctoral, Universidad de Deusto, Bilbao, España.

Lee, J. J. \& Hammer, J. (2011). Gamification in education: What, How, Why bother? Academic Exchange quarterly, 15. USA.

Mandoki, K (2006). Estética cotidiana y juegos de la cultura: Prosaica I. Siglo veintiuno editores. México.

Mc gonical, J., (2011). Reality Is Broken: Why Games Make Us Better and How They Can Change the World. Penguin Group : USA,

Newzoo (2018) Newzoo. Obtenido de https://newzoo.com/insights/infographics/mexicogames-market-2018/

Palillero, K (2012). Resumen: Caillois, Los juegos y los hombres, I-IV. Obtenido de: http:// timocratico.blogspot.com/2012/04/resumen-caillois-los-juegos-y-los.html

Portal web gamification.Com (2014): http://www.gamificacion.com/que-es-la-gamificacion.

Sepúlveda. G. (2016). Pokemon GO! y la muerte de los videojuegos: ¿sobreviviremos? Obtenido en: https://www.elmostrador.cl/agenda-pais/vida-en-linea/2016/07/13/pokemon-go-yla-muerte-de-los-videojuegos-sobreviviremos/

Zichermann, G., \& Linder, J. (2013). The gamification revolution: How leaders leverage game mechanics to crush the competition. McGraw Hill Professional. USA 


\begin{abstract}
Today, in the XXI century, Gamification (application of game thinking in nonludic contexts) has ceased to be a productivist methodology and has initiated a hard process of cultural colonization in those non-productive spaces. And today voices are emerging that demand that the Gamification appeal to much more, demanding to reach, even, life itself. This demand of overflowing can be translated into an unparalleled socio-political expansion of the codes and categories of culture, commonly linked to games and leisure. This colonizing phenomenon is called Trans-gamification. The present article will address its origins, as well as its philosophical and political projections.
\end{abstract}

Keywords: Gamification - Trans-gamification - leisure - game - society.

Resumo: Hoje, no século XXI, a gamificação (aplicação do pensamento do jogo em contextos não lúdicos) deixou de ser uma metodologia produtivista e iniciou um difícil processo de colonização cultural nesses espaços não produtivos. E hoje surgem vozes que exigem que a Gamificação atraia muito mais, exigindo alcançar, inclusive, a própria vida. Essa demanda de transbordamento pode se traduzir em uma expansão sócio-política inigualável dos códigos e categorias de cultura, comumente ligados a jogos e lazer. Este fenômeno colonizante é chamado Trans-gamification. O presente artigo abordará suas origens, bem como suas projeções filosóficas e políticas.

Palavras chave: Gamificação - Trans-gamificação - lazer - jogo - sociedade.

[Las traducciones de los abstracts fueron supervisadas por el autor de cada artículo] 